\title{
Effects of Freezing, Freeze-Drying and Cold Storage on the Size and Membrane Permeability of Multilamellar Liposomes*
}

\author{
Samir S. Abu-Zaid, Magotoshi Morii and Noriaki Takeguchi** \\ Faculty of Pharmaceutical Sciences, Toyama Medical and Pharmaceutical \\ University, Sugitani, Toyama, 930-01
}

(Recieved Sep. 22, 1983)

Freezing or freeze-drying caused a decrease in the liposome size and an increase in water permeability of large multilamellar liposomes made of phosphatidylcholine and cholesterol $(0 \%, 10 \%, 33 \%$ in mole ratio), but no size reduction with partially-sonicated liposomes. Cold storage at $-27^{\circ} \mathrm{C}$ up to 45 days resulted in no change in water permeability, although the proportion of fragmented liposomes increased. On the other hand, the cold storage caused significant increase in permeabilities of hydrophilic amino acids such as Gly and Pro with phosphatidylcholine multilamellar liposomes. These results indicate that freezing, freeze-drying, and cold storage induce an increase in the structural defect of lipid bilayer as well as increase in mobility (or disorder) of lipid bilayer.

Key words: Liposomes, Freezing, Freeze-drying, Storage, Permeability, Membrane defect

\section{Introduction}

It is widely accepted that, as a drug delivery system, liposomes have a number of applications. But, from the view of physical stability and storage of liposomes, liposomes are considered to have severe inconvenience for use in ordinary hospitals. One method to overcome this, is to store and transport liposomes at frozen or freezedried state together with or without cryoprotective materials. Generally speaking, these treatments are likely to increase membrane leakiness and/or to result in unstable liposomes. Several papers have been published about the effects of freezing, freeze-drying and cryoprotective materials for naturally occuring systems such as erythrocyte plasma membranes ${ }^{1,2)}$ and enveloped virus$\mathrm{es}^{3,4)}$ as well as liposomes ${ }^{5-8)}$.

*マルチラメラリポソームの粒子径と膜透過性に及ぼす 凍結, 凍結乾燥, 冷凍貯蔵の影響.

**サミロアブサイド，森井孫俊，竹口紀晃 : 富山医科薬 科大学薬学部 $=930-01$ 富山市杉谷
However, almost no paper has been published about effects of storage of liposomes on membrane permeabilities, possibly due to the requirement of prolonged experimental time. In this paper, effects of storage on permeabilities of water and amino acids and on the size of multilamellar liposomes were studied.

\section{Experimental}

\section{Materials}

A crude phosphatidylcholine (PC) was prepared from egg yolk of hens according to the procedure of Faure ${ }^{9)}$. The crude PC was furthermore purified using a silica gel column. The purified PC has one spot on a thin layer chromatogram. Cholesterol (Chol) was obtained from Sigma. All amino acids used were purchased from Wako. Polycarbonate membranes were from Nuclepore Corp.

\section{Preparation of liposomes}

Large multilamellar liposomes were prepared by the hand shaking method described by Bangham et al10). 
44 Abu-Zaid, Morii, Takeguchi: Freezing, Freeze-Drying and Cold Storage of Liposomes

Three types of liposomes: PC-only, PC-Chol (10\% in mole ratio) and $\mathrm{PC}-\mathrm{Chol}(33 \%)$, were made. The liposome suspension was made of $20 \mathrm{mM}$ sucrose, $4 \mathrm{mM}$. Piperazine-N, N'-bis(2-ethanesulfonic acid) (abbreviated as Pipes)-Tris buffer (pH 7.4) and $0.9 \mu \mathrm{mol} \mathrm{lipid} / \mathrm{m} l$. The suspension was passed through $3 \mu \mathrm{m}$ polycarbonate membrane just before measurements of the size and permeability to remove any aggregated large liposomes and dust.

Partially-sonicated liposomes were prepared by sonicating multilamellar liposomes in a bath type sonicator (Branson B-42) at $25^{\circ} \mathrm{C}$ for a total period of $30 \mathrm{~min}$ (Each $1 \mathrm{~min}$ sonication followed by $30 \mathrm{sec}$ cooling on ice). The suspension of small multilamellar liposomes was passed through a $0.2 \mu \mathrm{m}$ polycarbonate membrane.

\section{Freezing and freeze-drying of liposomes}

The slow freezing was carried out in a freezer $\left(-27^{\circ} \mathrm{C}\right)$. After different periods of storage $(1,7,14,30,45,60$, and 90 days) under nitrogen gas in the freezer, the frozen liposomes were thawed at room temperature. The suspension was passed through a polycarbonate filter.

The quick freezing, which was used only for the experiments listed in Table 2, was done by immersing a test tube including liposomes into liquid nitrogen for 3-4 min followed by storage in the freezer. The freezedried liposomes were obtained by freezing liposomes in the freezer followed by drying under vacuum for $12 \mathrm{~h}$. Then, the freeze-dried liposomes were stored in the freezer for the subsequent analysis. After the storage for the predetermined period, water was added to the freeze-dried liposomes to make $20 \mathrm{mM}$ sucrose and $4 \mathrm{mM}$ Pipes-Tris media.

\section{Water permeability}

Water permeability was measured by the method of light scattering at $25^{\circ} \mathrm{C}$ as described elsewhere ${ }^{11)}$. Briefly, the liposome suspension was mixed with an equal volume of the hypertonic $100 \mathrm{mM}$ sucrose solution (also buffered with $4 \mathrm{mM}$ Pipes-Tris at $\mathrm{pH} 7.4$ ) in a Durrum stopped flow spectrophotometer. The increase in the intensity of light scattering reflects the decrease in the liposome volume due to the osmotic shrinkage. The change in the light scattering, $Y$, is simulated by using the following equation;

$$
Y=A\left\{1-\left(1+\mu_{2 w} t^{2} / 2\right) \exp \left(-k_{w} t\right)\right\}
$$

where $k_{w}$ is the water permeability, $\mu_{2 w}$ is the second expansion coefficient for the cumulant expansion ${ }^{11,12)}$, $t$ is time and $A$ is the population constant.

\section{Amino acid permeability}

The rate constant of amino acid influx, $k_{A}$, was also determined by the method of light scattering11). The liposome suspension was mixed with an equal volume of $100 \mathrm{mM}$ amino acid $+20 \mathrm{mM}$ sucrose solution (buffered to $\mathrm{pH} 7.4$ ) at $25^{\circ} \mathrm{C}$. The change in the intensity of light scattering, monitored as the change in transmittance at $550 \mathrm{~nm}$, was recorded on a Tektronix storage oscilloscope and a servorecorder. The initial rapid shrinkage was followed by the slow reswelling due to aminc acid influx. The change in the intensity, $Y$, is simulated by using the following equation;

$$
\begin{aligned}
Y=A\{1 & \left.-\left(1+\mu_{2 w} \mathrm{t}^{2} / 2\right) \exp \left(-k_{w} t\right)\right\} \\
& \left.-1.2 A\left\{1-\mu_{2 A} t^{2} / 2\right) \exp \left(-k_{A} t\right)\right\}
\end{aligned}
$$

where $\mu_{2 A}$ is the another second expansion coefficient. The volume of maximally-swelled liposomes was about 1.2 times the initial unshrunken size ${ }^{11)}$, so the value of 1.2 was multiplied to $A$ for the reswelling process in equation 2 .

\section{Size of liposomes}

The mean diameter of liposomes was measured by the quasi-elastic light scattering (QELS) method as described by Morii et al13,14). The intensity of laser light scattering fluctuates due to the thermal motion of liposomes in the solution. We used a single clipping method to calculate the auto-correlation coefficient of the fluctuation ${ }^{15)}$. From the auto-correlation curve, the mean decay constant, $\Gamma$ was obtained by using the cumulative expansion method ${ }^{12)}$. The mean decay constant is related to the mean translational diffusion coefficient, $D_{\text {trans }}$;

$$
D_{\text {trans }}=\Gamma / K^{2} \text {, }
$$

and

$$
K=(4 \pi n / \lambda) \sin (\theta / 2)
$$

where $\lambda, n$ and $\theta$ are the wave length of incident light, the refractive index of solvent and the scattered angle, respectively. In our experiments, $\theta=90^{\circ}$. The mean radius of liposomes, $R$, is calculated from Stokes-Einstein equation:

$$
R=k T / 6 \pi \eta D_{\text {trans }}
$$

where $k, \eta$ and $T$ are the Boltzman constant, the vis- 
Table 1 Effects of freezing and freeze-drying on the size and water permeability of large multilamellar liposomes

\begin{tabular}{llcc}
\hline Liposomes & & mean diameter $(\mu \mathrm{m})$ & $k_{w}\left(\mathrm{sec}^{-1}\right)$ \\
\hline Phosphatidylcholine & Control & 0.69 & 0.32 \\
& Freeze-dried & 0.33 & 0.46 \\
& F1ozen & 0.41 & 0.34 \\
\hline Phosphatidylcholine+ & Control & 0.92 & 0.23 \\
10 mol \% cholesterol & Freeze-dried & 0.36 & 0.43 \\
& Frozen & 0.42 & 0.17 \\
\hline Phosphatidylcholine+ & Control & 1.36 & 0.29 \\
\hline 33 mol \% cholesterol & Freeze-dried & 0.38 & 0.22 \\
\hline
\end{tabular}

Control liposomes were stored at $4^{\circ} \mathrm{C}$ for 1 day.

Freeze-dried and frozen liposomes were stored at $-27^{\circ} \mathrm{C}$ for 1 day.

Table 2 Effects of freezing speed on the size of large and small multilamellar liposomes

\begin{tabular}{lcc}
\hline Liposomes & \multicolumn{2}{c}{ mean diameter $\begin{array}{c}(\mu \mathrm{m}) \\
\text { small liposomes } \\
\text { (partially sonicated) }\end{array}$} \\
\hline Control & large liposomes & 0.082 \\
Slowly frozen-then dried & 0.73 & 0.092 \\
Rapidly frozen-then dried & 0.36 & 0.091 \\
\hline
\end{tabular}

Liposomes were prepared from phosphatidylcholine only.

Control liposomes were stored at $4^{\circ} \mathrm{C}$ for 1 day, and freeze-d. ried liposomes were stored at $-27^{\circ} \mathrm{C}$ for 1 day.

osity of solvent and absolute temperature, respectively. The measurements were carried out at $25^{\circ} \mathrm{C}$. The apparatus was consisted of a He-Ne laser ( $5 \mathrm{mWatt}$, NEC), an optical cell with a rapid mixing (Union), a photomultiplier (R649, Hamamatsu TV), a photon counter (C-1230, Hamamatsu TV) and a microcomputer (TRS-80, Tandy).

\section{Lipid peroxidation during storage}

The lipid peroxidation of liposomes during storage was evaluated by the method of thiobarbituric acid assay ${ }^{16,17)}$. The lipid peroxidation in unsaturated fatty acids containing at least 3 double bonds lead to the formation of malondialdehyde ${ }^{16}$ ). Malondialdehyde reacts with thiobarbituric acid to give a red species absorbing at $535 \mathrm{~nm}$. The liposome suspension containing $1.0 \mathrm{mg}$ phospholipid $(4.0 \mathrm{ml})$ was mixed with $1.0 \mathrm{ml}$ of thiobarbituric acid reagent $(0.67 \%$ thiobarbituric acid + glacial acetic acid, $1: 1, \mathrm{v} / \mathrm{v}$ ) and heated at $95^{\circ} \mathrm{C}$ in oil bath for $60 \mathrm{~min}$. The absorbance of the sample was measured at $535 \mathrm{~nm}$ against a blank that contains all the reagents minus the liposomes.

\section{Results and Discussion}

Hereafter, the liposomes which were frozen- storedthawed are referred as "frozen liposomes" and the liposomes which were frozen - freeze-dried - stored - reconstituted as "freeze-dried liposomes".

\section{Effects of freezing on the size and water permeabili-} ty

In Table 1, results of freezing and freeze-drying on the size and water permeability of large multilamellar liposomes are listed. The mean diameter of control liposomes are much larger than those of freeze-dried and frozen liposomes for all types of liposomes studied, i.e., PC-only, 
46 Abu-Zaid, Morii, Takeguchi: Freezing, Freeze-Drying and Cold Storage of Liposomes

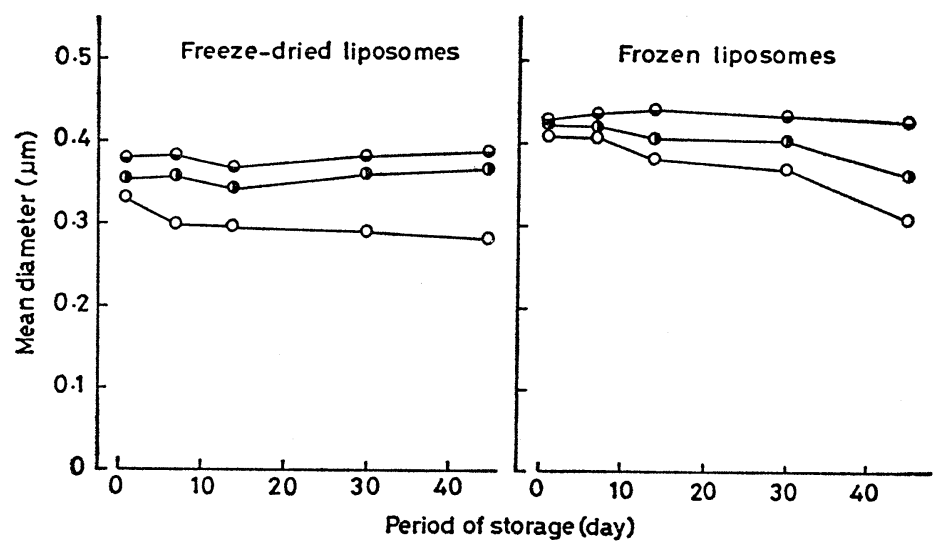

Fig. 1 Effects of cold storage at $-27^{\circ} \mathrm{C}$ on the average diameter of freeze-dried and frozen liposomes.

O, PC-only liposomes; I, PC-Chol (10\%) liposomes;

๑, PC-Chol $(33 \%)$ liposome

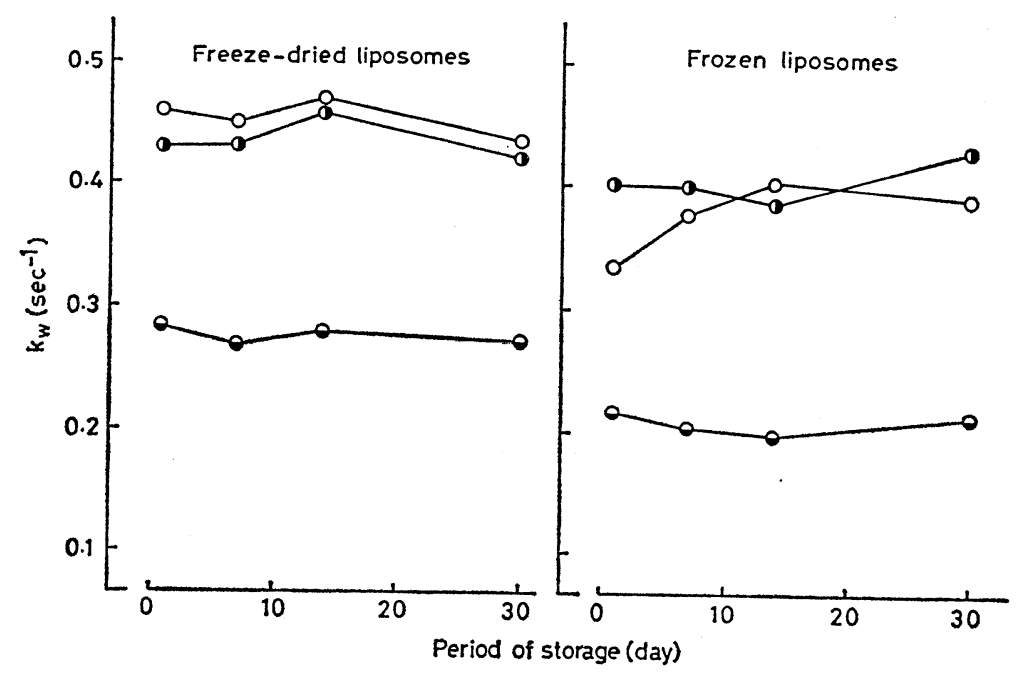

Fig. 2 Effects of cold storage at $-27^{\circ} \mathrm{C}$ on water permeability of freeze-dried and frozen liposomes.

○, PC-only liposomes; O, PC-Chol (10\%) liposomes;

$\ominus$, PC-Chol $(33 \%)$ liposomes

PC-Chol (10\%) and PC-Chol (33\%). As previously reported by usi4), for untreated liposomes, PC-Chol $(33 \%)$ liposomes have the largest diameter in comparison with other types of liposomes. The diameters of frozen and freeze-dried liposomes distribute in a narrow range of $0.33-0.43 \mu \mathrm{m}$, irrespective of the broad distribution of control liposomes which were stored at $4^{\circ} \mathrm{C}$ for 1 day, $0.69-1.36 \mu \mathrm{m}$ (Table 1 ). The size reduction caused by freezing or freeze-drying apparently accompanies the increase in water permeability (Table 1). This is consistent with the fact that freezing causes a pronounced increase in the release of both nonionic and ionic markers trapped in egg lecithin liposomes ${ }^{8}$.

In partially-sonicated liposomes, however, freezing did not produce any reduction in size as shown in Table 2. Furthermore, the size did not depend on the freezing 


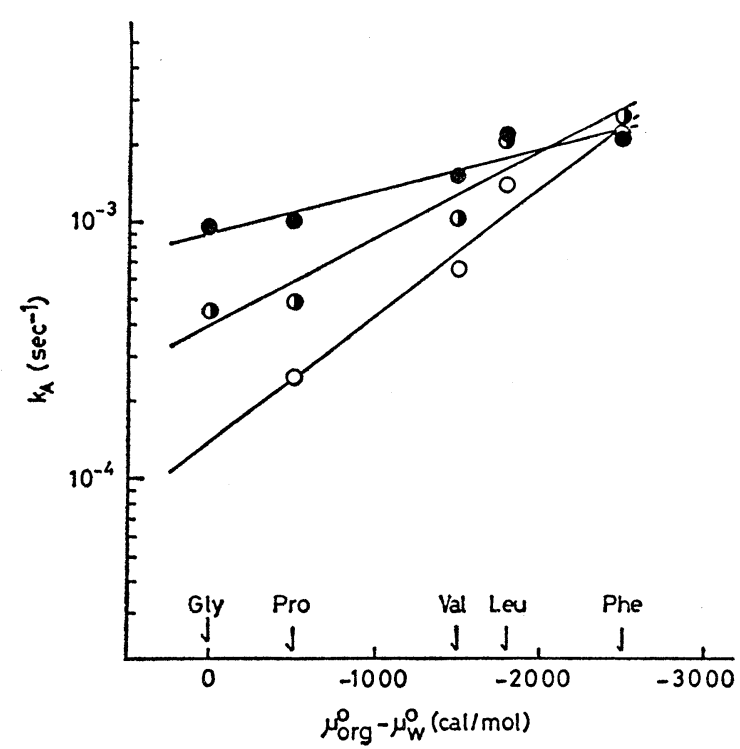

Fig. 3 Relationship between amino acid permeabiity, $\log k_{A}$, and the hydrophobicity scale, $\mu^{\circ}$ org $-\mu^{\circ}{ }_{W}$. PC-only multilamellar liposomes were used here.

$\bigcirc$, untreated liposomes which were stored at $4^{\circ} \mathrm{C}$ for 1 day;

D, frozen, then stored at $-27^{\circ} \mathrm{C}$ for 1 day;

- frozen, then stored at $-27^{\circ} \mathrm{C}$ for 30 days

rate.

Effects of cold storage at $-27^{\circ} \mathrm{C}$ on the size and water permeability

The diameter of liposomes is shown as a function of the storage period in Fig. 1. The size of freeze-dried liposomes stored at $-27^{\circ} \mathrm{C}$ does not change during the storage with PC-Chol (33\%) liposomes, and it decreased slightly with PC-Chol (10\%) and PC-only liposomes. But, the latter slight decrease with time may not be significant, because the size measured by the quasielastic light scattering is a function of not only intact liposomes but also fragmented liposomes. The relative proportion of the fragmented liposomes apparently increased during the storage, which was speculated from the finding that the osmotic response of stored liposomes decreased with the storage period (Data are not shown, since we did not try systematic experiments).

Water permeability of freeze-dried and frozen lipo-

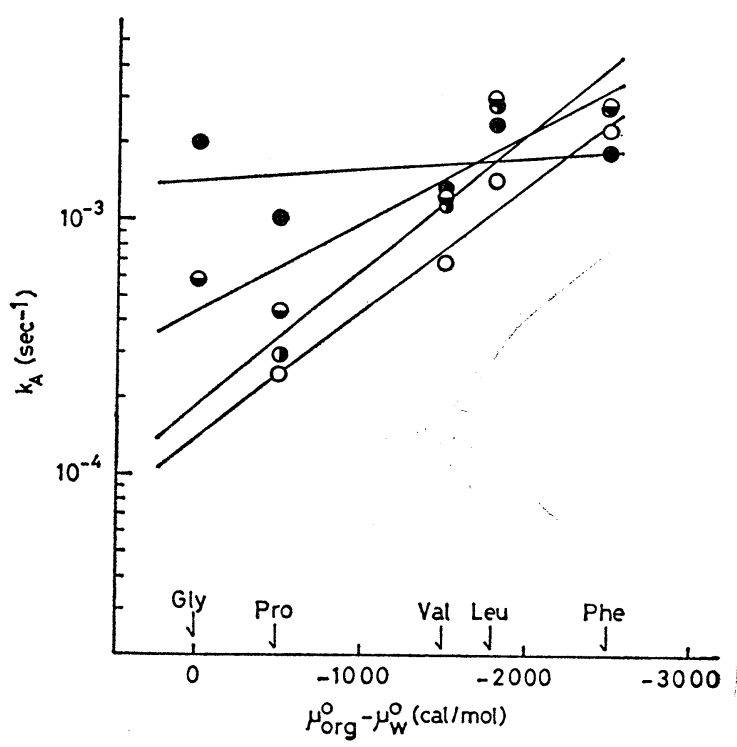

Fig. 4 Relationship between amino acid permeabilities, $\log k_{A}$, and the hydrophobicity scale, $\mu^{\circ}$ org $-\mu^{\circ}{ }_{W}$. PC-only multilamellar liposomes were used.

$\bigcirc$, unireated liposomes which were stored at $4^{\circ} \mathrm{C}$ for 1 day;

D, freeze-dried, then stored at $-27^{\circ} \mathrm{C}$ for 1 day;

- freeze-dried, then stored at $-27^{\circ} \mathrm{C}$ for 30 days;

- freeze-dried, then stored at $-27^{\circ} \mathrm{C}$ for 90 days

somes does not change during the storage up to 30 days (Fig. 2). It is noted that the measurement of water permeability is not affected by the presence of the fragmented liposomes, since only osmotically sensitive liposomes can shrink and give the change in the light scattering.

Effects of freezing, freeze-drying and storage of liposomes on amino acid permeability

As previously described ${ }^{13,14)}$, logarithm of amino acid permeability, $\log k_{A}$, is a linear function of a hydrophobicity scale. The linear relationship was reexamined using frozen, freeze-dried and stored liposomes (PConly). The order of permeability was Gly $<\mathrm{Pro}<\mathrm{Val}<$ Leu $<$ Phe. Freezing or freeze-drying the PC-only liposomes increased the value of $k_{A}$ for the hydrophilic amino acids such as Gly, Pro and Val, but not for the 


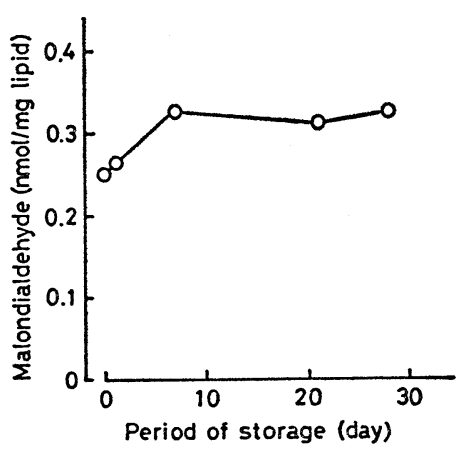

Fig. 5 Effects of cold storage at $-27^{\circ} \mathrm{C}$ on lipid peroxidation of frozen PC-only liposomes. The concentration of lipid peroxide was expressed in terms of malondialdehyde (nmol/mg lipid).

strong hydrophobic amino acids such as Leu and Phe (Figs. 3 and 4). Furthermore, prolonged storage induced an additional increase in $k_{A}$ for hydrophilic amino acids, but again not for hydrophobic amino acids.

These results suggest that the hydrophobic barriers such as the number of lamellae does not change, but the hydrophilic barriers such as mobility of acyl chains and structural defects in lipid bilayer increase during the freezing, freeze-drying and cold storage. As described earlier, water permeability of frozen and freeze-dried liposomes is constant during the storage up to 30 days (Fig. 2). Since water molecule is small and much hydrophilic is comparison with hydrophilic amino acids such as Gly and Pro, water permeability would be governed more by the extent of mobility (sometimes, referred as disorder or fluidity ${ }^{18)}$ ) of lipid bilayer than by structural defects of bilayer. Therefore, it is indicated that the cold storage per se increases mainly the extent of structural defect in lipid bilayer.

The ammount of peroxidized phospholipid in the PC-only frozen liposomes increased with storage time, especially at initial, as shown in Fig. 5. But no increase was observed for pure PC which was stored in chloroform at $-27^{\circ} \mathrm{C}$ for 3 weeks. This may be correlated with the occurring of the defect in the liposomal structure.

Finally, present studies would give protocol for experiments to examine the change in the membrane permeability during prolonged storage and to search liposomes which have practical stability for medical use.

\section{References}

1) A. K. Gulevsky, B. V. Sakharov, V. Y. Volkov: Biochim. Biophys. Acta, 728, 371 (1983)

2) G. F. Doebbler, A. P. Rinfret: Biochim. Biophys. Acta, 58, 449 (1962)

3) C. Wallis, J. L. Melnick: J. Virol., 2, 953 (1968)

4) P. Albrecht, H. P. Schumacher: Appl. Microbiol., 20, 160 (1970)

5) G. Strauss, E. P. Ingenito: Cryobiology 17, 508 (1980)

6) U. Pick: Arch. Biochem. Biophys., 212, 186 (1981)

7) D. L. Melchior, E. P. Bruggemann, J. M. Steim: Biochim. Biophys. Acta, 690, 81 (1982)

8) D. Siminovitch, D. Chapman: FEBS Letters, 16, 207 (1971)

9) M. Faure: Bull. Soc. Chem. Biol., 32, 503 (1950)

10) A. D. Bangham, M. M. Standish, J. C. Watkins: J. Mol. Biol., 13, 238 (1965)

11) N. Takeguchi, M. Morii, T. Kashiwagura, Y. Ishizuka, I. Horikoshi: Int. J. Pharmaceu., 9, 153 (1981)

12) D. E. Koppel: J. Chem. Phys., 57, 4814 (1972)

13) M. Morii, S. Abu-Zaid, N. Takeguchi: Yakugaku Zashi, 101, 1023 (1981)

14) M. Morii, S. S. Abu-Zaid, N. Takeguchi: Int. J. Pharmaceu. in press (1983)

15) J. C. Selser, Y. Yeh, R. J. Baskin: Biophys. J., 16. 337 (1976)

16) J. A. Buege, S. D. Aust.: "Methods in ENZYMOLOGY" Vol. LII (S. Fleisher, L. Packer, eds.) pp. 302-310, Acacemic Press, New York (1978)

17) K. Yagi: Biochem. Med., 15, 212 (1976)

18) M. K. Jain, R. C .Wagner: "Introduction to Biological Membranes" pp.87-92, John Wiley and Sons, New York (1980) 